\title{
How do new/recent mothers experience unwanted harm thoughts related to their newborn? A thematic analysis.
}

\section{Abstract}

Objective: The aim of this qualitative research study was to explore how new/recent mothers experience infant-related harm thoughts (IRHTs).

Background: New/recent mothers' experiences of intrusive, infant-related harm thoughts remain a taboo topic, yet several studies indicate such thoughts are common. Understanding the normal experience of such thoughts is needed to improve the postpartum experiences of mothers, and clinical practice. The aim was to elicit a fuller, critical understanding of the experience of harm thoughts in a mixed, non-clinical sample, exploring how they are understood, managed and shared by women.

Methods: Semi-structured interviews were conducted with eight new/recent mothers who had experienced IRHTs related to their youngest child, born within the last two years. Data were analysed with Thematic Analysis.

Findings: The results yielded three core themes: Heightened emotions; Constructions of motherhood and maternal identity; Costs and benefits of sharing.

Conclusion: Findings corroborate previous literature showing that IRHTs commonly occur among non-clinical postpartum mothers, highlighting their intense emotional impact, and barriers to women reporting them due to stigma. Results also highlighted ways in which the pervasive ideology of motherhood informed mothers' meaning-making of IRHTs. Some pathologised their IRHTs in order to maintain their 'good' mother identity. However, others reconfigured their maternal identity in response to IRHTs, through a constructive process of self-development. Recommendations include discussing the ideology of motherhood with pregnant women and partners and facilitating open, normalising discussion of IRHTs. 


\section{Introduction}

Infant-related harm thoughts (IRHTs) represent a common yet distressing aspect of the transition to parenthood (Abramowitz, Khandker, Nelson, Deacon, \& Rygwall, 2006; Abramowitz, Schwartz, \& Moore, 2003; Fairbrother $\&$ Woody, 2008). The term refers to unwanted, intrusive thoughts, images and impulses and these are not unique to new or recent mothers; they are reported by nearly $80 \%$ of people (Purdon \& Clark, 1993; Rachman \& De Silva, 1978). The content typically relates to current concerns (Klinger, 1996), usually elicited by stress and negative emotional states (Brewin, Hunter, Carroll, \& Tata, 1996; Wroe, Salkovskis, \& Richards, 2000).

Fairbrother \& Woody (2008) distinguished between accidental and intentional IRHTs. Accidental harm refers to a baby coming to harm without the mother's involvement or by accident and include suffocation, the baby falling/being dropped, illness, contamination and neglect (e.g. forgetting the infant in the car). Intentional harm refers to thoughts, images or impulses in which she actively harms her infant, for example screaming at or shaking the baby and infanticide (e.g. throwing the baby out the window). Such intrusions appear to peak in the initial postpartum weeks, especially for first-time mothers (Kim, Mayes, Feldman, Leckman, \& Swain, 2013), and are often accompanied by feelings of disgust (Abramowitz et al., 2006, 2003; Fairbrother \& Woody, 2008). Fairbrother \& Woody (2008) found that postpartum accidental IRHTs were reported by all 98 women in their study, while nearly half reported intentional IRHTs.

Within the literature, IRHTs are characterised as 'ego-dystonic'. This means IRHTs tend to be experienced as inconsistent with a mother's sense of self, therefore invoking horror, disgust and/or alarm, leading to distress. Careful assessment by a healthcare professional may distinguish between these intrusive, ego-dystonic thoughts from those that should activate safeguarding proceedings (Lawrence, Craske, Kempton, Stewart, \& Stein, 2017).

Fathers also report IRHTs. Abramovitz et al. (2003), found that nearly three 
quarters of mothers and two thirds of fathers in their study of 117 parents in the US experienced IRHTs. One fifth of mothers and nearly a quarter of fathers reported intentional IRHTs. In a subsequent study (Abramowitz et al., 2006) of 43 mothers and 42 fathers, $90 \%$ of the participants reported accidental IRHTs while approximately one third reported intentional IRHTs. In a UK study involving 158 women, 60\% reported thoughts about their baby dying (Hall \& Wittkowski, 2006).

Several studies have identified stress as key in initiating and maintaining IRHTs. Infant crying was established as a significant trigger for experiencing intentional IRHTs in primiparous mothers in Canada (Fairbrother, Barr, Pauwels, Brant, \& Green, 2015). Fairbrother \& Woody (2008) found high parenting stress and low perceived social support were both associated with intentional IRHTs. IRHTs tend to be conceptualised within a cognitivebehavioural framework. For example, if a mother "misappraises" an unwanted intrusion to drown her child as signifying an evil nature and intent to act this out, the thought itself will evoke high levels of distress (Fairbrother \& Abramowitz, 2007). The associated fear and distress then provoke efforts to avoid activities that elicit the thought (e.g. being alone with the infant), or to conduct compulsive rituals to "neutralise" the cognition (Abramowitz, Schwartz, Moore, \& Luenzmann, 2003; Abramowitz et al., 2003). Although both IRHTs and clinical obsessions may lead to attempts to control the thought (Larsen et al., 2006), the former tend not to be associated with behavioural compulsive rituals. Unwanted IRHTs also differ from clinical obsessions in OCD in that they are more fleeting, less upsetting and easier to dismiss (Fairbrother \& Woody, 2008).

Many mothers and healthcare professionals are unaware of the prevalence of IRHTs (Brok et al., 2017). This often compounds mothers' feelings of shame and guilt, resulting in non-disclosure (Barr \& Beck, 2008; Fairbrother \& Woody, 2008). Mothers also fear that their baby may be removed from them by statutory services, suggesting that prevalence rates are likely underestimated (Lawrence et al., 2017). 
IRHTS are common and not associated with risk yet tend to be pathologised, evoking shame and anxiety to those experiencing them. The pervasive influence of the CBT model as it has been applied to IRHTs and the tendency to conceptualise IRHTS as similar to OCD lacks perspective. Examining IRHTs within a wider socio-cultural context would allow exploration of how cultural discourses, such as around the 'good' mother ideology, play into mothers' experiences of these thoughts. Few studies have accounted for cultural pressures and subsequently emerging notions of maternal ambivalence, in the context of IRHTs. Therefore, this research aimed to develop a fuller understanding of the experience of IRHTs in a mixed, nonclinical sample, exploring how they are understood and shared by women. 


\section{Method}

\section{Participants}

Eight new/recent mothers, all of whom had experienced IRHTs related to their most recently born baby, participated.

Table 1. Participant demographics

\begin{tabular}{|c|c|}
\hline Pseudonym & Demographic Information \\
\hline Kayleigh & 29, White British ${ }^{1}$. One child, 20 months. \\
\hline Salma & 33, Asian. Two children, aged four and two years. \\
\hline Fee & 40, White British. One child, 23 months \\
\hline Hannah & 34, White British. One child, six months. \\
\hline Lucy & 34, White British. Two children, aged two and four months. \\
\hline Polly & 41, British Greek-Cypriot. Two children, aged three and one. \\
\hline Malia & 32, Nepalese. One child, aged one. \\
\hline Yvette & $\begin{array}{l}\text { 46, "mixed" race (German/West Indian). Four children, aged } \\
21 \text {, nine, six and } 23 \text { months. }\end{array}$ \\
\hline
\end{tabular}

\footnotetext{
${ }^{1}$ Ethnicities self-identified
} 


\section{Procedure}

Participants were recruited through children's centres, mother and baby groups and baby classes. Adverts were also circulated in libraries, childfriendly cafes and breastfeeding clinics across North London. Those interested in participating contacted the researcher for further information. Exclusion criteria were age of baby exceeding 24 months, pre-term delivery, receiving or had received treatment for depression/other psychological difficulties, non-English speaking.

Ethical approval was obtained from the University of East London and all participants provided written consent. Each participant received a £10 Amazon voucher.

\section{Data collection}

A semi-structured interview schedule was based on existing literature and discussions with clinicians and researchers. This covered experiences of IRHTs (how these described, managed and shared), hopes and expectations about motherhood and women's experiences of being parented. An introductory preamble reiterated to participants that unwanted IRHTs are common among new mothers giving specific examples. Interviews, ranging from 54 to 117 minutes, were conducted by the first author (a mother and trainee clinical psychologist). Six were conducted by telephone and two participants were interviewed in person.

\section{Analysis}

Interviews were audio-recorded, transcribed verbatim and anonymised. Square brackets containing three dots indicated removal of text not relevant to the point. Data were coded by the first author using inductive thematic analysis, following the steps set out by Braun and Clark (2006). Initial codes were organised into potential themes in an ongoing, iterative process. This led to considering relationships between codes and potential themes to form overarching themes and subthemes (Braun \& Clarke, 2006). The coding 
scheme and analysis were independently reviewed by the second author and aspects of the analyses discussed to reach a consensus.

Our analysis is grounded in a critical realist epistemology, recognising both that IRHTs materially affect participants but that the context for and understanding of IRHTs is shaped by socio-cultural and political assumptions and beliefs (Pilgrim \& Bentall, 1999). 


\section{Results}
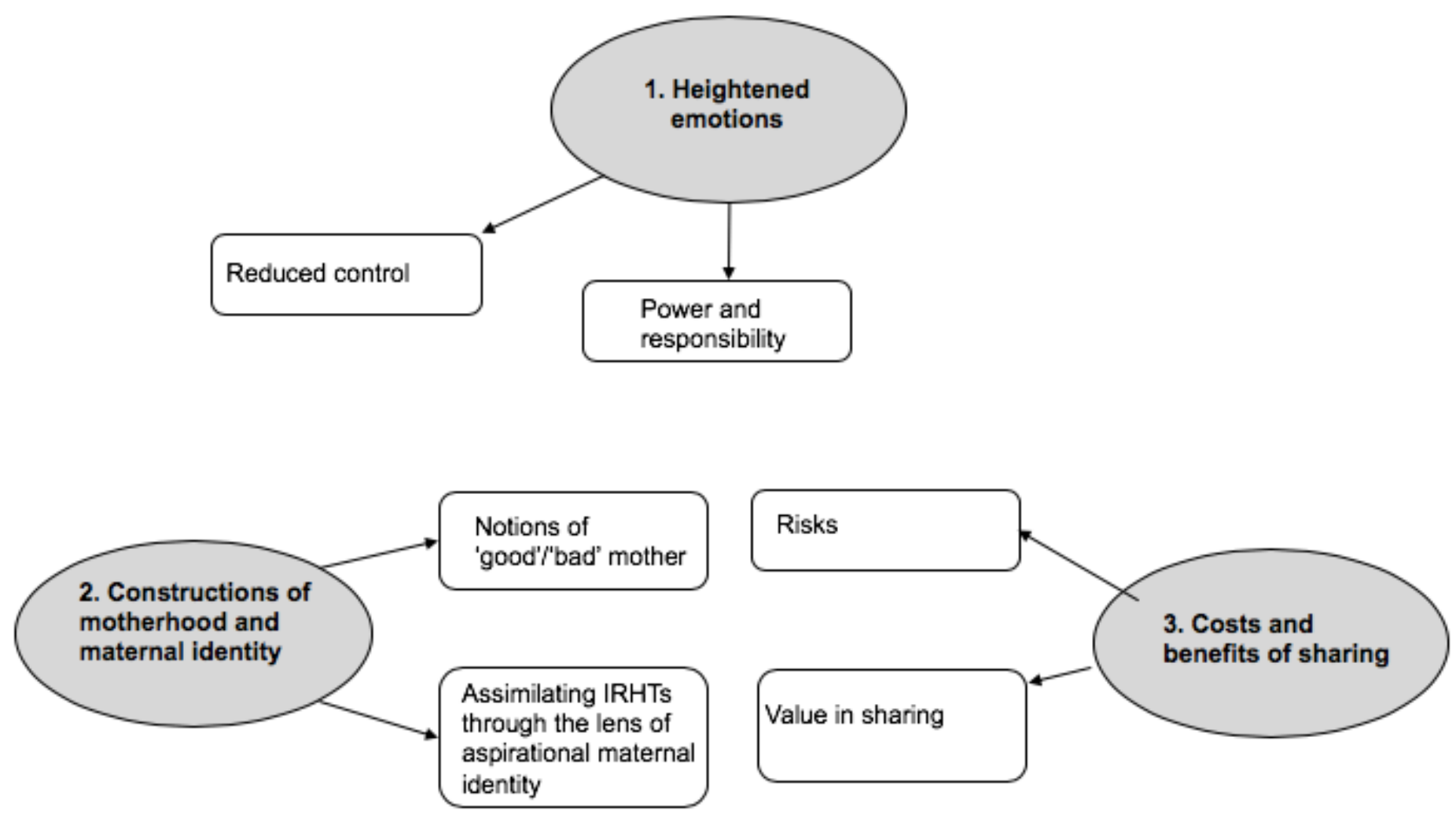

Figure 1: Thematic map illustrating three themes and six subthemes constructed from the analysis 
The analysis developed three core themes and six sub-themes: Figure 1.

\section{Heightened emotions}

The women describe experiencing an overwhelming lack of control as their IRHTs occurred.

"You almost couldn't control them at all [...] it's almost soul-destroying." YVETTE

They deployed various strategies to manage this. Some engaged in self-dialogue to try and manage IRHTs through rationalising them. Most also described behavioural responses that helped increase their sense of control, including distraction (e.g. making a cup of tea), and washing the baby's belongings if they had become 'contaminated'.

P: A lack of control with my environment [...] I felt like I had to have more control over it. So everything had to be washed yeah, and clean for her. LUCY

Two participants described the emotionally exhausting impact of feeling unable to "switch off" from experiencing IRHTs, even when someone else was caring for the baby.

"I had to watch him constantly, he was a very small baby and I thought it would take a few seconds for him to smother himself [...]" SALMA

The second subtheme related to the complex, double-edged nature of participants' experience of responsibility: a sense of their own power combined with acute awareness of the vulnerability of the baby. IRHTs arose in interaction with these and, for some, were accentuated by a sense that the baby was not yet a complete person.

“...l just felt this overwhelming feeling of protectiveness. And anything that I thought may be harmful [...] like smoke or things like that, I kind of just wanted to protect her from them." LUCY 
"...I suddenly had the realisation that I could pinch him if I wanted to, like it was kind of testing the boundaries of the power I had over him [...] 'cos in the early days they don't really feel like a person [...]" HANNAH

“...My little girl's vagina was in front of me, and thinking how small it is, and thinking how innocent this baby and child is, and how anybody could even go there, or touch that inappropriately [...]" POLLY

Another woman described the nuances around this power dynamic, in which she felt powerless to repeatedly resist urges to throw her baby from a sheer drop. She compared reliance on her "will power" to prevent her from acting on her impulse to suicidal ideation:

“... One side of you has this urge to do something and you're stopping yourself from doing it. I certainly don't have, I hadn't had [...] felt like that, and I kind of put it down to what people feel like when they want to commit suicide and then they actually, they then do it." YVETTE

\section{Constructions of motherhood and maternal identity}

Participants described replicating some aspects of their own mother, but rejecting others to create their own notion of a "good" mother:

"I'd like to be a calm mother, not get too worked up, or raise my voice, definitely not a physically hands on mother. Because I had a mother who was, so l've always thought 'I'm never going to be that mother'." POLLY

These experiences intersected with cultural representations and discourses that helped shape an aspirational maternal identity. Most reported using Google to look up information about babyhood. Extensive access to information was recognised as both helpful and fuelling IRHTs. Similarly, comments on forums such as Mumsnet or Netmums were found to be both "helpful or really quite disturbing and judgemental" 
(Lucy). Discussions of SIDS and advice warning against co-sleeping related to three mothers' IRHTs:

"I think the rolling on him was because it was very much drummed into you about not co-sleeping and how dangerous it is to co-sleep, even though they then say, many families do co-sleep and it's safe if you follow these rules." HANNAH

Early experiences and wider cultural understandings intersected, placing pressures on participants to live up to their internalised model of a 'good' mother, which often clashed with the reality.

"I wanted to be one of these mothers who's really hands on with everything, found everything really easy, you know, if I love my children, everything will be easy, everything would be the perfect picture but in reality, it's a lot of hard work." SALMA

Yvette experienced her IRHTs as incongruent to her 'good' mother ideal.

"I just felt nuts, and like you say, you didn't trust yourself, you didn't know how to deal with all these emotions. You didn't feel like a good, normal person anymore $[. .$.$] "YVETTE$

Yvette described struggling to manage the frightening tussle with her darker impulses.

"...At times you felt you know when you were walking down the stairs, holding her, you just kept going 'I'm not going to throw her, I won't, I won't' [...] I just felt like I was on guard all the time."YVETTE

Hannah described the distressing spiral of thoughts following an initial impulse to pinch her son:

“...And I wonder if it's a little bit, 'If I pinch him, will I feel it, No I won't'. And then also as soon as l'd had that thought 'If I pinch him, will it hurt me - no it 
won't', this secondary going, 'Oh my goodness, you wanted to pinch your child, do you want to pinch your child, are you a danger to your child, are you going to hurt your child?" HANNAH

Some participants who had or continued to work in healthcare were able to integrate their desired maternal identity with the stresses and strains of motherhood's lived reality. Consequently, their IRHTs were experienced as congruent and 'part of' them. This process was illustrated by ways they characterised their IRHTs as arising from a particular context without concluding that they might reflect their fitness as a mother. They were able to reconcile IRHTs with a reconfigured 'good' mother identity.

"So at least if I did have thoughts of harm coming to X I didn't think 'Oh that's going to happen' or 'Oh I'm a bad parent', yeah I was able to not go down that path. Probably working in mental health maybe helped a bit in that sense, not to be too overwhelmed with them." FEE

Their experiences of IRHTs were accompanied by strong emotions, but they facilitated a constructive process of enhancing self-awareness. Polly described her IRHT concerning child sexual abuse (CSA) as "upsetting" but it led her to discontinue working with sex offenders as a psychologist. For Kayleigh, her experience of selfdevelopment following an impulse to shake her son signified a "turning point" in her mothering approach.

"...I was being swayed by the things I was worried I should be doing, like everyone else's baby has slept right through the night since [they were] 5 minutes old, and that stress [....] This feeling that this isn't working and has to change, and that change was me being probably the kind of mother I wanted to be in the first place." KAYLEIGH

Malia's experiences of IRHTs allowed her to reconcile her experience of motherhood six months postpartum with her pre-baby 'fantasy' ideal. She could then understand the paradoxical nature of motherhood, as both good and bad and crucially, accept her IRHTs as representing some of these negative aspects. 
"I see lots of mums socially and I feel like I'm quite honest, like maternity leave is not this holiday, like it is hard work, and it's hard, and I don't like being in the house all day, I have to go out at least once a day, so the way I rationalise it is, it's not a holiday, you get stressed at work, so it's normal to be stressed outside of work, and so thus those thoughts might happen [...] I've just thought, you know, being a mum isn't easy, everyone struggles with it, thus this experience l've had is normal so, I'm fine." MALIA

\section{Costs and benefits of sharing}

Participants had not shared their IRHTs with healthcare professionals and those who confided in a partner or friend limited disclosure. For some feelings of shame provoked anxiety about being judged negatively.

"Female friends who hadn't had children, I didn't [think] they'd completely understand [...] I thought they would worry for me, and whether I was ok with my baby, and I didn't want that extra anxiety [...] I didn't want to put fear in someone else's head that I couldn't cope with my children." SALMA

Decisions not to share IRHTs with healthcare professionals were grounded in fears of being perceived as a risk to their baby.

P: "...For me to just go to a Health Visitor "I wanted to pinch my baby the other day, it would make it into a massive deal' [...]

I: And what would you be worried that they might do?

$P$ : I think they'd start monitoring and watching me [...] Yeah, yeah, my big worry would be that they'd take the baby away..." HANNAH

Those who felt able to share with family or friends spoke of it's value.

"...She said she'd had them with all three of her children and as soon as she said that I thought 'Oh! Thank god!' [...] 'Thank god somebody has said it. Thank god she's being open about it'." SALMA 
"...I would recommend to speak to somebody [...] I felt like my will power was so strong that I got through it, but you almost don't know if you would have so I kind of would recommend someone to try and speak to somebody, you know a Health Visitor or somebody, I certainly wish I did at the time." YVETTE 


\section{DISCUSSION}

The literature distinguishes between accidental and intentional IRHTs (e.g. (Fairbrother \& Woody, 2008), and both types were described in this study. Consistent with previous findings, the majority of participants (six in total) reported accidental IRHTs, not all of which related to their own actions. These included suffocation, the baby falling or accidentally being dropped from a high surface, contamination, and accidentally being responsible for harm coming to the baby (e.g. through the baby drowning) (Abramowitz et al., 2006; Abramowitz, Schwartz, \& Moore, 2003; Fairbrother \& Woody, 2008; Hall \& Wittkowski, 2006). Half of the sample reported intentional IRHTs, ranging from impulses to shake or smother the baby or throw the baby from a height, to an impulse to pinch the baby.

Commonalities in the nature of intentional thoughts have been found previously, including physical harm and infanticide (Fairbrother \& Woody, 2008; Murray \& Finn, 2012). These IRHTs have been reported less commonly than accidental IRHTs such as contamination (Fairbrother \& Woody, 2008). The present study is the first to explicitly distinguish between sources of intentional harm described as either external or endogenous. In the former case, two participants conceptualised sources of external threat as predators or perpetrators posing a public risk, through snatching or violently attacking themselves and/or their children. Both participants related their IRHTs directly to high-profile murders covered in the media (the Jamie Bulger case and that of Rachel Nickell). Understandably these IRHTs, which reflect every parent's worst nightmare and were recalled from news coverage some years ago, induced considerable anxiety and distress. Although such cases are extremely rare they can give rise to a "culture of fear", that can influence parental anxiety (Franklin \& Cromby. J., 2009).

Consistent with previous studies (e.g. Fairbrother et al., 2015), all participants reported a powerful emotional response to IRHTs. They described diminished control, related both to limited controllability of thoughts and the chaotic, overwhelming nature of adjusting to life with a new baby. 
Participants deployed strategies, such as self-dialogue, to help them manage their IRHTs. Previous research has also identified this strategy (Abramowitz et al., 2006; Abramowitz, Nelson, Rygwall, \& Khandker, 2007; Larsen et al., 2006). Some participants employed reappraisal of the meaning of their IRHTs. Larsen's study (2006), which viewed IRHTs as mapping onto the contemporary OCD model (Salkovskis et al., 1999), related this strategy to parents reappraising their IRHTs in negative ways, leading them to think they were a bad parent. In our study some participants equated their IRHTs with 'badness' and spoke of their IRHTs, intensifying feelings of distress, sadness, anxiety, fear and shame. This, however, needs to be seen in the light of prevalent framings of motherhood as discussed above. Participants also described responses to their IRHTs that was very similar to CBT strategies. This apparent in the terminology used to describe their responses, such as "distraction", "strategies to manage" and "behavioural responses". This is not to suggest that participants were consciously or selectively deploying CBT techniques, as they were not framed as such, but more that these cognitive and behavioural responses are widely recognised and available.

None of the women in this study reported harsh or abusive behaviour towards the infant in response to IRHTs. This finding corroborates research consistently showing that ego-dystonic thoughts experienced postpartum do not reflect intention to harm, and therefore do not represent increased risk of violence (Brok et al., 2017;

Fairbrother \& Woody, 2008; Lawrence et al., 2017).

As elsewhere (e.g. Murray \& Finn, 2012), participants described the double-edged nature of the mother-infant power differential, positioning themselves as both a potential source of harm to and defender of their babies. Rather than expressing an "unconscious wish", as Freud might have concluded, Stadlen (2004) acknowledges the challenge for new mothers faced with choosing to use her power for good or bad, life or death. Intentional IRHTs can be viewed as helping mothers delineate clear boundaries between what is morally acceptable and what is not, serving as an "effective warning system" (Stadlen, 2004, p.50). Vivid images or impulses to hurt the baby accidentally or intentionally can represent natural fears that the infant will die through carelessness or inadequacy, thereby prompting mothers to increase their vigilance (Fairbrother \& Abramowitz, 2007; Leckman et al., 1999). 
Our participants learnt gradually over time how to protect their babies, learning to tolerate their anxiety to help them grow more confident in their positions of power.

What came across perhaps most powerfully was the influence of cultural discourses on participants' desired maternal identities. The ways in which women drew heavily on the pervasive Western ideology of motherhood as a critical aspect of femininity (Stoppard, 2000) constituted an important backdrop to their assimilation of their IRHTs. This social construction of motherhood as idyllic, desirable, natural, and ultimately fulfilling to women, existing as selfless nurturers, has repeatedly been highlighted (e.g. (Choi, Henshaw, Baker, \& Tree, 2005; Nicolson, 2001; Woollett \& Marshall, 2000). Cultural representations portraying only positive images set the standard for what is a 'good' mother (and therefore a good woman) and what comprises a 'bad' one. This ideology has been shown to influence women's expectations of motherhood, and when confronted with the reality, must accept that they cannot meet this ideal which produces conflict (Choi et al., 2005; Mauthner, 1999). For all participants, assimilation of their IRHTs was powerfully influenced by their internalised models of the 'good' (and therefore 'bad') mother, which shaped their desired maternal identity.

Participants managed conflicts between these idealised concepts and the reality of motherhood in different ways. Half defended against their IRHTs by externalising or pathologising them because such thoughts clashed with their desired maternal identity. These women attempted to explain their IRHTs in terms of something that was experienced as alien and 'other' or the fault of 'another side of me'.

For the others their IRHTs signified deeper self-knowing and some acknowledgement of maternal ambivalence (Parker, 1995). These findings identify different ways women showed agency in resisting the ideology of motherhood to reconcile conflict involving the gap between myth and reality. This meant that their IRHTs were experienced as congruent, understood to arise out of a particular context and not signifying maternal "badness". These findings corroborate Mauthner's (1999) study showing women to be agentic in resisting the ideology of motherhood, but contrast with Choi et al.'s (2005) study, which found no evidence of 
agency and therefore resistance to this construction. However, the process of adjustment through experiencing IRHTs remains emotionally challenging. It is not easy for women to move fluidly "in and out of intense emotional states" with no cost to her psychological wellbeing (Baraitser, 2009, p.51).

Evidence of participants drawing on other dominant cultural discourses to augment their own notions of 'good' mothering was also informed by prescriptive medical advice, offering 'correct' ways to parent. Some participants directly related their IRHTs to SIDS, expressing profound fears around co-sleeping lest it result in infant death. Risk-focused advice around SIDS is yet another factor contributing to 'paranoid parenting' (Furedi, 2001). Such advice also belongs to the process of 'familiarisation' (Rose, 1990), in which experts "shore up the mechanisms of the state that take a 'policing' role towards mothers and fathers. The social and healthcare services take on responsibility for the assessment of good and bad ways to be parents". (Nicolson, 2001, p.133).

Most participants felt more able to share accidental than intentional IRHTs. None had shared either kind of IRHTs with a healthcare professional, but those who spoke to a partner or friend limited disclosure. Four identified fears around being judged as failing to cope and therefore a risk to their babies, leading them to self-censor talk with other mothers. Breen (1975) highlighted women's tendencies towards selfsilencing and self-policing when struggling to adhere to internalised idealised constructions of the calm, coping mother. In a society where postnatal distress positions women as 'mad' or 'abnormal', one can understand why women selfcensor themselves in this way. Participants were performing gender 'correctly' (Butler, 1990) by masking their IRHTs and related feelings to take up the discourses of the "Supermum, superwife, supereverything" mother (Choi et al., 2005, p.177). IRHTs have been associated with distress, guilt and shame, likely compounded by being poorly understood by healthcare professionals and little talked about generally (Brok et al., 2017; Lawrence et al., 2017).

As in previous research (e.g. Lawrence et al., 2017) fear of having their child removed by statutory services underlay women's decision not to inform healthcare professionals. Participants who felt able to share their IRHTs described the benefits 
of having their experience "normalised", consistent with previous studies (e.g. Lawrence et al, 2017).

\section{Conclusions and recommendations}

Culturally shared, idealised constructions of the 'good' mother inform women's experiences of IRHTs, and reluctance to share with others. This tendency should be discussed with prospective parents to help them understand their normalcy, their own experiences of such thoughts, and to be open about IRHTs with others. Feeling isolated can intensify IRHTs, therefore sharing experiences in support groups can help to normalise and validate such thoughts.

Clinicians should receive guidance in distinguishing between a mother expressing thoughts that may indicate potential harm and IRHTs, which are not associated with risk (Lawrence et al., 2017). Increasing awareness of IRHTs, not currently asked about routinely in perinatal assessment (NICE, 2017), will help clinicians to facilitate open, sensitive discussions with mothers.

All participants were self-selected and from broadly similar socio-economic backgrounds, identifying predominantly as middle-class, educated and married/cohabiting. Five were employed, in training or had worked in healthcare, and it is possible that they possessed some specialist knowledge around intrusive thoughts. Nevertheless, richness and diversity was evident across women's accounts, and balance as women described both accidental and intentional IRHTs. Both class and race (Braun, Vincent, \& Ball, 2008; Reynolds, 2001) are likely to influence women's experiences of IRHTs. Therefore, future research should aim to recruit participants from broader socio-economic and racial/ethnic backgrounds. The experiences partners and of those in women's support networks should also be explored. 


\section{References}

Abramowitz, J. S., Khandker, M., Nelson, C. A., Deacon, B. J., \& Rygwall, R. (2006). The role of cognitive factors in the pathogenesis of obsessive-compulsive symptoms: A prospective study. Behaviour Research and Therapy, 44(9), 13611374. https://doi.org/10.1016/j.brat.2005.09.011

Abramowitz, J. S., Nelson, C. A., Rygwall, R., \& Khandker, M. (2007). The cognitive mediation of obsessive-compulsive symptoms: A longitudinal study. Journal of Anxiety Disorders, 21(1), 91-104. https://doi.org/10.1016/j.janxdis.2006.05.003

Abramowitz, J. S., Schwartz, S., \& Moore, K. (2003). Obsessional thoughts in postpartum females and their partners: Content, severity, and relationship with depression. Journal of Clinical Psychology in Medical Settings, 10(3), 157-164. https://doi.org/10.1023/A:1025454627242

Abramowitz, J. S., Schwartz, S., Moore, K. M., \& Luenzmann, K. R. (2003). Obsessive-compulsive symptoms in pregnancy and the puerperium: A review of the literature. Journal of Anxiety Disorders, 17(4), 461-478. https://doi.org/10.1016/S0887-6185(02)00206-2

Baraitser, L. (2009). Maternal encounters: The ethics of interruption. London: Routledge.

Barr, J. A., \& Beck, C. T. (2008). Infanticide secrets: Qualitative study on postpartum depression. Canadian Family Physician, 54(12).

Braun, A., Vincent, C., \& Ball, S. J. (2008). "I'm so much more myself now, coming back to work" - Working class mothers, paid work and childcare. Journal of Education Policy, 23(5), 533-548. https://doi.org/10.1080/02680930802054370

Braun, V., \& Clarke, V. (2006). Using thematic analysis in psychology. Qualitative Research in Psychology, 3(2), 77-101.

https://doi.org/10.1191/1478088706qp063oa

Breen, D. (1975). The birth of a first child: Towards an understanding of femininity. London: Tavistock publications.

Brewin, C., Hunter, E., Carroll, F., \& Tata, P. (1996). Intrusive memories in depression: an index of schema activation? Psychological Medicine, 26, 12711276.

Brok, E. C., Lok, P., Oosterbaan, D. B., Schene, A. H., Tendolkar, I., \& van Eijndhoven, P. F. (2017). Infant-related intrusive thoughts of harm in the 
postpartum period: A critical review. The Journal of Clinical Psychiatry, 78(8), e913-e923. https://doi.org/10.4088/JCP.16r11083

Butler, J. (1990). Gender trouble: Feminism and the subversion of identity. New York: Routledge.

Choi, P., Henshaw, C., Baker, S., \& Tree, J. (2005). Supermum, superwife, supereverything: Performing femininity in the transition to motherhood. Journal of Reproductive and Infant Psychology, 23(2), 167-180. https://doi.org/10.1080/02646830500129487

Fairbrother, N., \& Abramowitz, J. S. (2007). New parenthood as a risk factor for the development of obsessional problems. Behaviour Research and Therapy, 45(9), 2155-2163. https://doi.org/10.1016/j.brat.2006.09.019

Fairbrother, N., Barr, R. G., Pauwels, J., Brant, R., \& Green, J. (2015). Maternal thoughts of harm in response to infant crying: an experimental analysis. Archives of Women's Mental Health, 18(3), 447-455. https://doi.org/10.1007/s00737-014-0471-2

Fairbrother, N., \& Woody, S. R. (2008). New mothers' thoughts of harm related to the newborn. Archives of Women's Mental Health, 11(3), 221-229. https://doi.org/10.1007/s00737-008-0016-7

Franklin, L., \& Cromby. J. (2009). Everyday fear: Parenting and childhood in a culture of fear. The Many Forms of Fear, Horror and Terror, 161-174. Retrieved from

http://citeseerx.ist.psu.edu/viewdoc/download?doi=10.1.1.627.4285\&rep=rep1\&t ype $=$ pdfpage $=176$

Furedi, F. (2001). Paranoid parenting: Abandon your anxieties and be a good parent. London: Allen Lane.

Hall, P. L., \& Wittkowski, A. (2006). An exploration of negative thoughts as a normal phenomenon after childbirth. Journal of Midwifery and Women's Health, 51(5), 321-330. https://doi.org/10.1016/j.jmwh.2006.03.007

Horowitz, M. J. (1975). Intrusive and repetitive thoughts after experimental stress. Archives of General Psychiatry, 32(11), 1457. https://doi.org/10.1001/archpsyc.1975.01760290125015

Kim, P., Mayes, L., Feldman, R., Leckman, J. F., \& Swain, J. E. (2013). Early postpartum parental preoccupation and positive parenting thoughts: Relationship with parent-infant interaction. Infant Mental Health Journal, 34(2), 
104-116. https://doi.org/10.1002/imhj.21359

Klinger, E. (1996). The contents of thoughts: Interference as the downside of adaptive normal mechanisms in thought flow. In I. G. Sarason, G. R. Pierce, \& B. R. Sarason (Eds.), Cognitive interference: Theories, methods, and findings. (pp. 3-23). Mahwah: Lawrence Erlbaum Associates.

Larsen, K. E., Schwartz, S. A., Whiteside, S. P., Khandker, M., Moore, K. M., \& Abramowitz, J. S. (2006). Thought control strategies used by parents reporting postpartum obsessions. Journal of Cognitive Psychotherapy, 20(4), 435-446. https://doi.org/10.1891/jcpiq-v20i4a007

Lawrence, P. J., Craske, M. G., Kempton, C., Stewart, A., \& Stein, A. (2017). Intrusive thoughts and images of intentional harm to infants in the context of maternal postnatal depression, anxiety, and OCD. British Journal of General Practice, 67(661), 376-377. https://doi.org/10.3399/bjgp17X692105

Leckman, J. F., Mayes, L. C., Feldman, R., Evans, D. W., King, R. A., \& Cohen, D. J. (1999). Early parental preoccupations and behaviors and their possible relationship to the symptoms of obsessive-compulsive disorder. Acta Psychiatrica Scandinavica, 100, 1-26. https://doi.org/10.1111/j.16000447.1999.tb10951.x

Maimon, A. L. S. (2012). Ego-dystonic, obsessive thoughts of harm in postpartum women: An interpretative phenomenological analysis. The Wright Institute.

Mauthner, N. (1999). “Feeling low and feeling really bad about feeling low": Women's experiences of motherhood and postpartum depression. Canadian Psychology/Psychologie Canadienne, 40(2), 143-161. https://doi.org/10.1037/h0086833

Murray, L., \& Finn, M. (2012). Good mothers, bad thoughts: New mothers' thoughts of intentionally harming their newborns. Feminism and Psychology, 22(1), 4159. https://doi.org/10.1177/0959353511414015

NICE. (2017). Antenatal and postnatal mental health: clinical management and service guidance | Guidance and guidelines | NICE. Retrieved from https://www.nice.org.uk/guidance/cg192/chapter/1-recommendations

Nicolson, P. (2001). Postnatal depression: Facing the paradox of loss, happiness and motherhood. Chichester: Wiley-Blackwell.

Niler, E. R., \& Beck, S. J. (1989). The relationship among guilt, dysphoria, anxiety and obsessions in a normal population. Behaviour Research and Therapy, 
27(3), 213-220.

Parker, R. (1995). Torn in two: Mothering and ambivalence. London: Virago.

Parkinson, L., \& Rachman, S. J. (1981). Part II. The nature of intrusive thoughts.

Advances in Behaviour Research and Therapy, 3(3), 101-110.

https://doi.org/10.1016/0146-6402(81)90008-4

Pilgrim, R., \& Bentall, D. (1999). The medicalisation of misery: A critical realist

analysis of the concept of depression. Journal of Mental Health, 8(3), 261-274.

https://doi.org/10.1080/09638239917427

Purdon, C., \& Clark, D. A. (1993). Obsessive intrusive thoughts in nonclinical

subjects. Part I. Content and relation with depressive, anxious and obsessional

symptoms. Behaviour Research and Therapy, 31(8), 713-720.

https://doi.org/10.1016/0005-7967(93)90001-B

Rachman, S., \& De Silva, P. (1978). Abnormal and normal obssesions. Behaviour

Research and Therapy, 16(4), 233-248.

https://doi.org/10.1016/j.brat.2006.05.005

Reynolds, T. (2001). Black mothering, paid work and identity. Ethnic and Racial

Studies, 24(6), 1046-1064. https://doi.org/10.1080/01419870120077968

Rose, N. S. (1990). Governing the soul: The shaping of the private self. London ;New

York: Routledge.

Salkovskis, P., Shafran, R., Rachman, S., \& Freeston, M. H. (1999). Multiple pathways to inflated responsibility beliefs in obsessional problems: possible origins and implications for therapy and research. Behaviour Research and Therapy, 37(11), 1055-1072. https://doi.org/10.1016/S0005-7967(99)00063-7

Stadlen, N. (2004). What mothers do: Especially when it looks like nothing. London:

Piatkus.

Stoppard, J. M. (2000). Understanding depression: Feminist social constructionist approaches. Feminism and Psychology (Vol. 20). London: Routledge.

https://doi.org/10.1177/0959353509359966

Woollett, A., \& Marshall, H. (2000). Motherhood and mothering. In J. M. Ussher

(Ed.), Women's health: Contemporary international perspectives (p. 506).

Leicester: British Psychological Society.

Wroe, A. L., Salkovskis, P. M., \& Richards, C. (2000). "Now I know it could happen, I have to prevent it": A clinical study of the specificity of intrusive thoughts and the decision to prevent harm. Behavioural and Cognitive Psychotherapy, 28(1), 63- 
70. 